\title{
Living Mesolithic Time: Narratives, Chronologies and Organic Material Culture
}

\author{
Ben Elliott ${ }^{1} \cdot$ Seren Griffiths $^{2}$
}

Published online: 22 June 2018

(C) The Author(s) 2018

\begin{abstract}
British and Irish Mesolithic studies have long been characterized by a reliance on broad-scale lithic typologies, both to provide chronologies, and in discussion of 'cultural' groups. More recently, traditional narrative structures-period definitions of 'Early' and 'Late', or culture typologies-have been complemented by a host of other evidence. This has included new studies of site stratigraphy, evidence for seasonality, and material culture chaîne opératoire chronologies, which place a greater emphasis on both temporal precision and the lived experiences of Mesolithic peoples. This paper will consider how the study of organic artefacts forces these narrative scales into acute focus, and presents an opportunity to explore the challenges in synthesizing different forms of data. We discuss how the evidence from sites in Ireland and Britain allows for new approaches, and highlight some of the challenges that this evidence presents, not least the perennial issue of moving from site-specific data to broader narratives. While the nature of earlier prehistoric evidence makes this an especially obvious issue for Mesolithic studies, it is one which generally besets archaeology. We suggest that in order to move beyond this in earlier prehistoric studies specifically, we need to make better use of all evidence sources, however seemingly prosaic, including antiquarian collections in museums, and chance and casual finds. Only by including the raft of available data, and recognizing its utility beyond the sum of individual apparently uninspiring parts, can we begin to move from generalizing narratives to more nuanced archaeological understandings of past material worlds.
\end{abstract}

Ben Elliott

ben.elliott@york.ac.uk

Seren Griffiths

SGriffiths7@uclan.ac.uk

1 Department of Archaeology, University of York, York, UK

2 Department of Archaeology, School of Forensic and Applied Science, University of Central Lancashire, Preston, UK 
Keywords Mesolithic $\cdot$ Chronology $\cdot$ Organic $\cdot$ Narrative

\section{Introduction}

Mesolithic studies are marked out from other lines of archaeological enquiry by the antiquity of the evidence, and the relative imprecision of our chronologies. This imprecision is in contrast with the precision of microscale chronologies at individual sites, raising issues of wider relevance for early prehistory more generally. This paper will examine organic material culture from a series of Irish and British Mesolithic sites in order to explore our understanding of this period. We consider the ways in which chronologies derived from these organic artefacts influence our conceptualization of the period as a whole, and the issues raised when tacking between the specific evidence sets from individual sites and wider regional and temporal datasets.

\section{Timing the Mesolithic of Britain and Ireland}

Since Westropp's (1866) initial definition of the term 'Mesolithic' in relation to lithic typology (and later subsistence modes: Westropp 1872), there has been a tension between the singular eventful chronology of the short-scale and the seemingly enduring long-term of the Mesolithic. The first published reference to the 'Mesolithic' appears in the report of a paper delivered on behalf of Westropp (1866) to the Anthropological Society, and was possibly influenced by Worsaae's developed Stone Age chronology (first outlined in 1861), which included a period between the Palaeolithic and Neolithic (Gräslund 1987, p. 38). This report pre-dates a more thorough working of Westropp's thesis (Westropp 1872; Rowley-Conwy 1996; Zvelebil 1998; Daniel 1967, p. 260), in which the term 'Mesolithic' (or other nomenclature) is avoided in favour of a series of 'stages'.

Traditional Mesolithic scales of analysis in Ireland and Britain have emphasized a coarsely defined narrative, couched in terms of broad periodizations based on culture-historical approaches to defining material culture. These are classically articulated as the Early/Middle/Late/Final Mesolithics (e.g. Clark 1932; Mitchell 1955, 1970; Woodman 1977, 1978; Jacobi 1978; Barton and Roberts 2004), which form the backbone of systematic studies. Within these studies, an emphasis on the atypical records from individual sites has included a focus on the seasonal quality of human lifeways, which often emphasized subsistence (e.g. Legge and RowleyConwy 1988), using material culture forms as proxies for absent faunal and floral records away from these select sites (e.g. Mellars 1976; Woodman 1977).

Recent methodological developments have re-emphasized fine-scale approaches to Irish and British Mesolithic lifeways through the application of refitting studies (Conneller 2005), use-wear analysis (Dumont 1988); fine-grained dating of palaeoenvironmental events (Griffiths and Robinson 2018); and more precise chronologies for individual sites and technological innovations (e.g. Milner 1999; Waddington 2007; Bayliss and Woodman 2009; Griffiths 2014). These, combined with a growing focus on sociality and personhood (e.g. Finlay 2006; Conneller 
2006), have arguably led to more well-rounded appreciations of Mesolithic lifeways, better suited to addressing the day-to-day aspects of social practice.

These shifts lead to obvious discontinuities between the chronological scales of our analyses. The contrast to this emphasis on the short-term event can be seen with our pre-existing understanding of later hunter-gatherers, where 'the Mesolithic' appears to assume the mantle of 'time immemorial'. This narrative structure in part originates within lithic-derived periodizations. We would do well to remember that, as a description, 'the Mesolithic' should be regarded as an 'old, imperfect terminology for the sake of [facilitating] communication' (Zvelebil 2002, p. 128; cf. Pluciennik 2002, p. 117). When we apply the term 'Mesolithic' to a period or thing we can find in the archaeological record, we create 'Mesolithic time', an undifferentiated temporal block.

But does this tension within the study of the Mesolithic in Britain and Ireland matter? We would argue that it does. As with other areas of earlier prehistory, where there are notable differences between the precision afforded by microscale analysis of evidence and the very long duration of the period, there is a risk that the specific is abstracted into the general due to an absence of evidence. Rather than adopting this as an intellectual approach (e.g. Bailey 2007 and references therein) that is applied to data, we consider that these issues can inadvertently structure narratives that fail to adequately deal with the diversity of the records. In a period where a very limited number of sites have produced both organic and inorganic material for analysis, or pristine in situ anthropogenic deposits, there is a real danger that narratives become dominated by chronologically and spatially very limited datasets. As with Palaeolithic studies, there is the tendency to get 'sucked in', so that key 'type-sites' become 'the Mesolithic' writ large (cf. Lane and Schadla-Hall 2004). Our inability to move between the specific narratives of individual sites creates the potential for generalizations to be smeared across regions and time periods, a topic explored in the debate regarding the representative nature of the Mesolithic human skeletal remains record in Britain and Ireland (Richards et al. 2003; Milner et al. 2006).

A further consequence of this scalar tension is the focusing of research on moments of transition between periodizations (Myers 1987; Costa et al. 2005; Conneller et al. 2012), leaving the issues of diversity or dynamism within a block of time neglected. In contrast to the 'static' character of life within these periodized blocks of time, we are often faced with the binary flip-switch at the interface between 'the Mesolithic' and adjacent periods. In this scenario, our explanatory models in part become confused with the artefactual imprecision of our data. We see this in Clark's model of the end of Mesolithic lifeways in Britain, where he writes that 'analysis of transition presented material culture as evidence for rapid and "wholesale" change', and that the 'farming economy and the whole complex of technology, practices and ideas that made up our Neolithic culture must have been introduced from overseas' (Clark 1966, p. 176; our emphasis), and we can contrast this with recent developments in the understanding of both the timing and tempo of change subsequently (cf. Whittle et al. 2011).

Is it not ironic that a field of study which is defined by being in the middle-the Mesolithic_seems wholeheartedly unable to deal with the middle term, the 
chronological and explanatory leap that bridges the gap between our ability to see short term change, and long term tradition? Where apparent patterns of behavioral continuity exist, either across or within a period, we turn to the enduring appeal of 'persistent places' (Barton et al. 1995; Spikins 2002). Here repeated presence within a landscape becomes abstracted from a palimpsest of stone tools or features, but is rarely articulated in terms of the specific cultural choices which lead to groups of people returning to a location over the medium and long term. It is rare to find 'the bit in the middle' articulated in narratives beyond the scale of the site, or the reduction sequence we have identified within an assemblage. The limited number of attempts to break apart internal periodizations on radiocarbon grounds have suffered from a lack of data and a somewhat crude approach to calibration (Reynier 2005), and whilst more nuanced studies have recently begun to make progress in modelling internal technological shifts within the British Early Mesolithic (Conneller et al. 2016), these still follow the typo-technological distinctions outlined in earlier models. We suggest that this is partially a result of the data available to archaeologists studying the Mesolithic, and partially about the perceived limits of interpretation which Mesolithic archaeologists choose to adopt. Surprisingly, we are frequently dishonest about the limitations of our chronological resolution, what David Clarke termed 'the kinked and distorted time services of the chronological scales' (Clarke 1973, p. 10).

Mesolithic archaeology faces important and peculiar challenges in terms of creating robust chronologies, and in applying these chronologies to generate thoughtful narratives. As mentioned above, the issues of working from the specific to the general-or perhaps better, from the specific to the middle ground narratives-are especially acute in Mesolithic studies. It may be significant that these discussions of lumping or splitting, of categorization, and how to use it but not be defined by it, have been ongoing since the very concept of the Mesolithic was first developed. We argue that in order to move beyond these short or long-term approaches, we need to be more creative, and more explicit about the limitations of our evidence when writing about the nature of continuity, tradition and change in the Mesolithic.

When we engage critically with variability over time and space, the limitations of our current 'cultural' concepts are highlighted (Zvelebil 2002). Such critical approaches continue a pattern of research into variability in material culture types identified by Switsur and Jacobi (1979). This is vitally important, as without sufficient temporal precision, our perceptions of how people actually lived in Mesolithic times are abstracted and impoverished, with implications for our causal narratives.

How then are we to negotiate these scales, which are especially pertinent to Mesolithic studies? We believe that a false distinction has been drawn between the perceived longevity of the 'Mesolithic' and the very fine-grained evidence from individual locations. This is an issue where the orders of magnitude are greater for the Mesolithic (and other areas of earlier prehistory), but actually we are engaged with the same fundamental issues of interpretation-of moving from evidence to narrative-as other areas of archaeology. We believe that one way to overcome these potential narrative biases lies in critically exploring our existing datasets, in 
actively attempting to differentiate between the specific and the general, and in maintaining open minds with regard to elements of the archaeological record that provide the potential to question existing interpretations. We need to attempt to work across scales critically, to acknowledge the noise in our data and the space for ambiguity in our understandings. Above all, we emphasize that our causal narratives do not have to be simplistic, should perhaps be actively challenged, and certainly should emphasize creative and imaginative approaches.

In this paper we use the recent evidence from three sites in Ireland and Britain to explore how we write about Mesolithic material. These case studies emphasize the importance of chronologies in the ways we write about Mesolithic people. By combining two slightly disparate aspects of the discipline-organic material culture and radiocarbon measurements - and questioning our presuppositions, we hope to recognize the challenges that still face us, and to make tangible the ways in which these limitations can structure the narratives that we produce.

\section{Time and Organic Artefacts}

While Mesolithic chronologies have predominantly been established by lithic typologies, organic material culture has played an essential role in defining and characterising the Mesolithic in Britain and Ireland. The initial recognition of Early Holocene bone and antler artefacts was viewed as scientifically informative from two key perspectives in the nineteenth century. Firstly, as a biostratigraphic marker, differentiating between cold-adapted species (such as reindeer and horse) and more temperate-adapted species (such as red deer, elk, wild boar or aurochs) was seen as a key method for distinguishing between Pleistocene and Holocene deposits within Irish and British cave sequences (Burkitt 1926; Woodman et al. 1997). This allowed the species of bone and antler artefacts to further contribute towards the dating of deposits within a sequence-the flipping of one of the earliest binary switches mentioned above. Secondly, within these cave sequences, the presence of bone and antler artefacts was seen as a clear indicator of human activity-distinguishing between biological and anthropological 'blocks' of time within a coarse-grained narrative.

An appreciation of an organic component to the Mesolithic material culture repertoire in Britain can be traced back to Bishop's (1914) dating of the Obanian shell midden sites in western Scotland to the pre-farming Early Holocene. In Ireland, Woodman's work at Newferry established that a series of bone points dredged from the River Bann (May 1939; Whelan 1951) were deposited within Zone 5 (Woodman 1977). These 'Bann points' began to be tentatively thought of as Mesolithic, but the lack of typological parallels or stratigraphic security has, until recently, prevented a more precise understanding of their chronological distribution. They remained 'floating' in time throughout the Irish Mesolithic, even as discussions of typological and chronological relationships between Ireland and Europe-and the internal periodization of the Irish Mesolithic as a wholeprogressed apace (Mitchell 1955, 1970; Woodman 1977, 1978, 1981). Similar finds of bone and antler artefacts dredged from the River Thames (Lawrence 1929) were 
initially coarsely defined as Mesolithic, on the basis of typological similarities with material culture from southern Scandinavia (Clark 1932; Lacaille 1966), rather than any secure stratigraphic correlation.

The excavation of extensive evidence for bone, antler and wood working at Star Carr, Yorkshire, established a central role for the production of organic material within the emerging idea of British Mesolithic economies (Clark 1954). The excavation demonstrated a focus on the use of red deer antler to produce barbed projectile points, as well as the use of elk metapodials to manufacture batons, elk antler to create mattocks, and aurochs ulnae to produce scraping tools. In terms of wooden artefacts, a birchwood paddle was the only formal item listed by Clark, alongside a quantity of felled timbers. Further identification of split and intentionally aligned timber 'planks' at Star Carr in 1989 broadened the academic appreciation of carpentry in the British Mesolithic (Mellars and Dark 1998). However, the scarcity of preserved worked wood in the archaeological record for this period has until recently prevented discussions of its significance in Britain (though the recently excavated Carlisle Northern Development Route, and further work at Star Carr, will develop these understandings).

In Ireland, direct evidence for the use of wood in the creation of structures and fish traps has only emerged relatively recently (Warren et al. 2013). The excavation of waterlogged sites in Lough Kinale, Westmeath (Fredengren 2009), the River Liffey, Dublin (McQuade and O'Donnell 2007), and Cowanstown, Meath (Fitzgerald 2007; Mossop 2009) has produced basket fish traps, stake alignments and wattle fencing, prompting discussions over the form and function of the structures themselves, and their potential contribution to understanding Mesolithic forestry management practices (Warren et al. 2013).

Smith's (1989) work on a typo-chronology for the largely unstratified bone and antler 'mattocks' of Mesolithic Britain marks an important development for the chronological conceptualisation of organic material culture in the UK. Notably, Smith did not go so far as to link the phases of his chronology to specific "cultural groups' (perhaps reflecting an abatement of this style of thought towards the end of the twentieth century in Britain and Ireland), and the typo-chronology produced was ultimately based on a very small number of available pre-filtration radiocarbon dates, pollen dating, and typological parallels with better-dated material from Scandinavia. This approach was later contested by Bonsall and Smith (1989, 1992, 1999; Bonsall et al. 1995), who produced direct radiocarbon measurements on 67 pieces of modified bone and antler. This work radically challenged many of the previous assumptions concerning the chronological range of specific artefact types in Britain, with the realisation that uniserial barbed points spanned both the late Upper Palaeolithic and the Early Mesolithic, and that the vast majority of Smith's mattock types A and B were in fact much later, falling into the British Late Neolithic and Early Bronze Age.

These findings had profound implications for the application of European typochronologies to material in Britain. The realisation that the classic Scandinavian cultural sequence might not be applicable within a British context emphasises the importance of narratives that operate in the middle ground, between the immediate chronologies of the site and the long chronologies of the period. 
In contrast, the impact of Accelerator Mass Spectrometry (AMS) measurements on unstratified organic artefacts in Ireland has broadened the suite of material cultures believed to belong to the Irish Mesolithic and confirmed the typological chronologies for Mesolithic material culture. Following Woodman's work at Newferry 3, further AMS dating of a sample of Bann bone points has produced unanimously Mesolithic dates (Fig. 1; Table 1), leading to a growth in confidence in the Mesolithic affinities of all these finds (Woodman 2015).

Further emphasis on precision and the importance of specific temporal narratives can be seen in the development of chaîne opératoire approaches to osseous material culture elsewhere in Europe (David 1999). These approaches have been applied to finds from Ireland (David et al. 2015) and Britain (Elliott 2013), and place the technical actions involved in the sourcing, working, use and deposition of bone and antler within a chaîne opératoire narrative. These mark time in their own distinctive way, often developing a chronological sequence of actions and decisions for

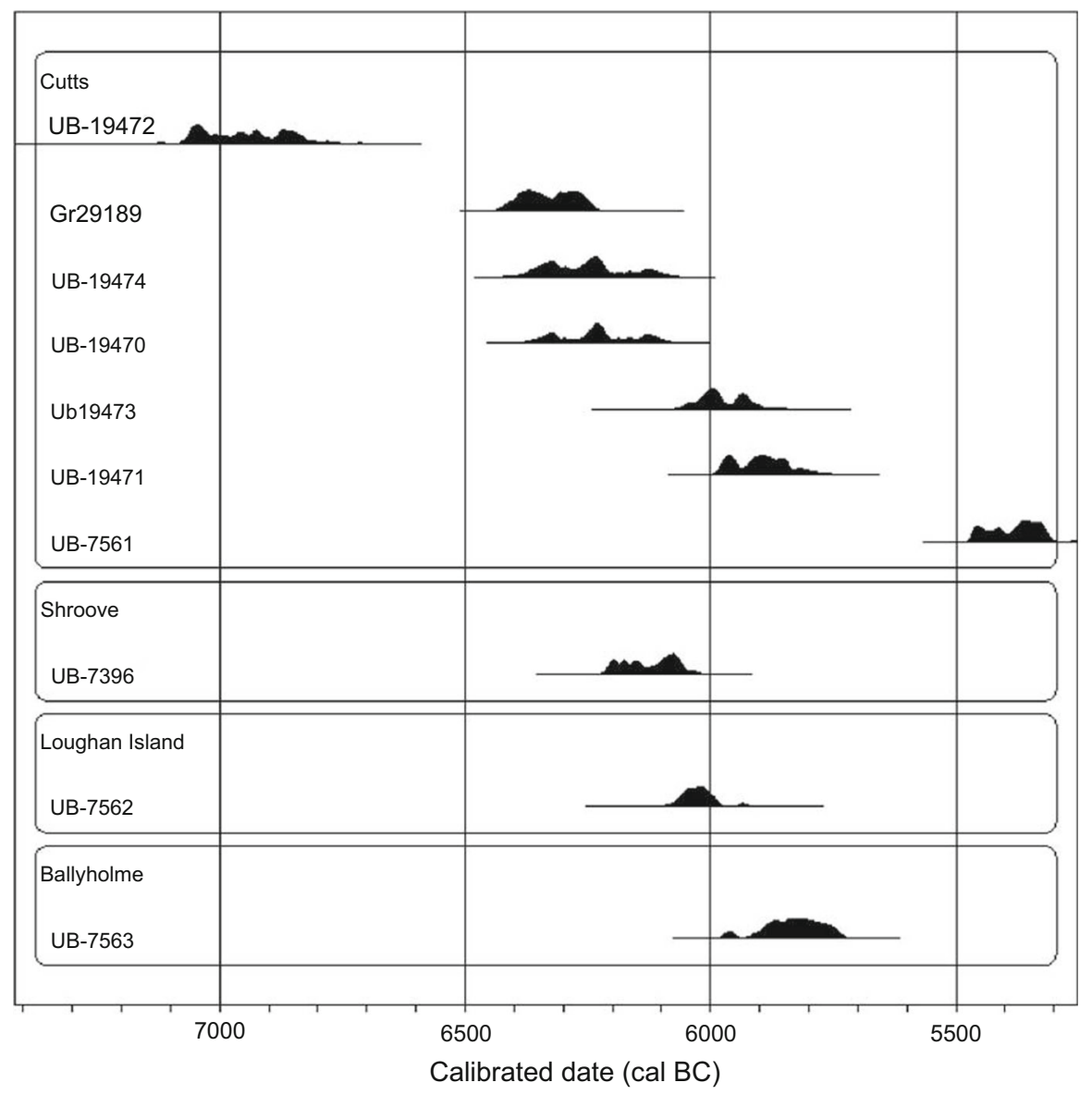

Fig. 1 Direct AMS dates from a sample of bone points dredged from the River Bann, Ulster, Northern Ireland (Woodman 2015) 
Table 1 Radiocarbon measurements on bone points from the River Bann

\begin{tabular}{llll}
\hline Site & Lab code & Date & $\begin{array}{l}\text { Calibrated BC date range (intercept; } \\
\text { rounded out by 10 years; 95\% confidence) }\end{array}$ \\
\hline Cutts & GR29189 & $7460 \pm 40$ & $6430-6230$ \\
Cutts & UB-7561 & $6386 \pm 40$ & $5480-5300$ \\
Loughan Island & UB-7562 & $7157 \pm 43$ & $6080-5930$ \\
Ballyholme & UB-7563 & $6949 \pm 45$ & $5980-5720$ \\
Cutts & UB-19470 & $7363 \pm 40$ & $6370-6090$ \\
Cutts & UB-19471 & $7004 \pm 40$ & $5990-5780$ \\
Cutts & UB-19472 & $8033 \pm 49$ & $7080-6770$ \\
Cutts & UB-19473 & $7103 \pm 45$ & $6060-5890$ \\
Cutts & UB-19474 & $7376 \pm 48$ & $6390-6090$ \\
Shroove & UB-7396 & $7246 \pm 32$ & $6220-6030$ \\
\hline
\end{tabular}

individual objects, based on the microstratigraphy of working marks, use traces and taphonomic processes.

The utility of radiocarbon dating, and other scientific chronological approaches, lies not fundamentally in the importance of temporal sequence, but in the ability of these methods to take us out of our cultural boxes, and to allow us to talk about human cultural choices and lifeways beyond the scale of the site and between the scale of the event and period. With the advent of AMS, for the first time individual finds could be directly dated. This work demonstrated what archaeologists have long known, but often fail to acknowledge explicitly: that material culture and human lifeways can be both spatially and temporally variable.

\section{Case Studies}

In the three case studies presented here, we discuss the importance of moving between different temporal scales to critically explore aspects of Mesolithic archaeology at Clowanstown (County Meath, Ireland); Staines (Surrey, England); and Sand (Highlands, Scotland).

\section{Clowanstown, County Meath, Ireland}

Excavated in 2004 as part of the M3 roads project, a series of four wooden fish traps were discovered at Clowanstown, Meath. Occupation at this small extant lake has been radiocarbon dated to 5320-4990 cal. BC and 5000-4720 cal. BC (Beta231957 and Beta-231948 based on two direct dates from the fish traps; Fig. 2; Table 2). The site comprises a range of wooden features, a consolidated platform and diagnostically late Mesolithic microliths (Mossop 2009). The traps themselves were made from alder, birch and rose wood, with branches and stems cut at 1-2 years old (Warren et al. 2013). The use of the fish traps to exploit migratory 
marine resources, moving through the Irish freshwater networks in summer and autumn, is widely accepted within the conventional frameworks of Mesolithic subsistence strategies (Woodman 2015; although see Little 2014). All four traps were made using an open twining basketry technique, with pairs of transverse wefts

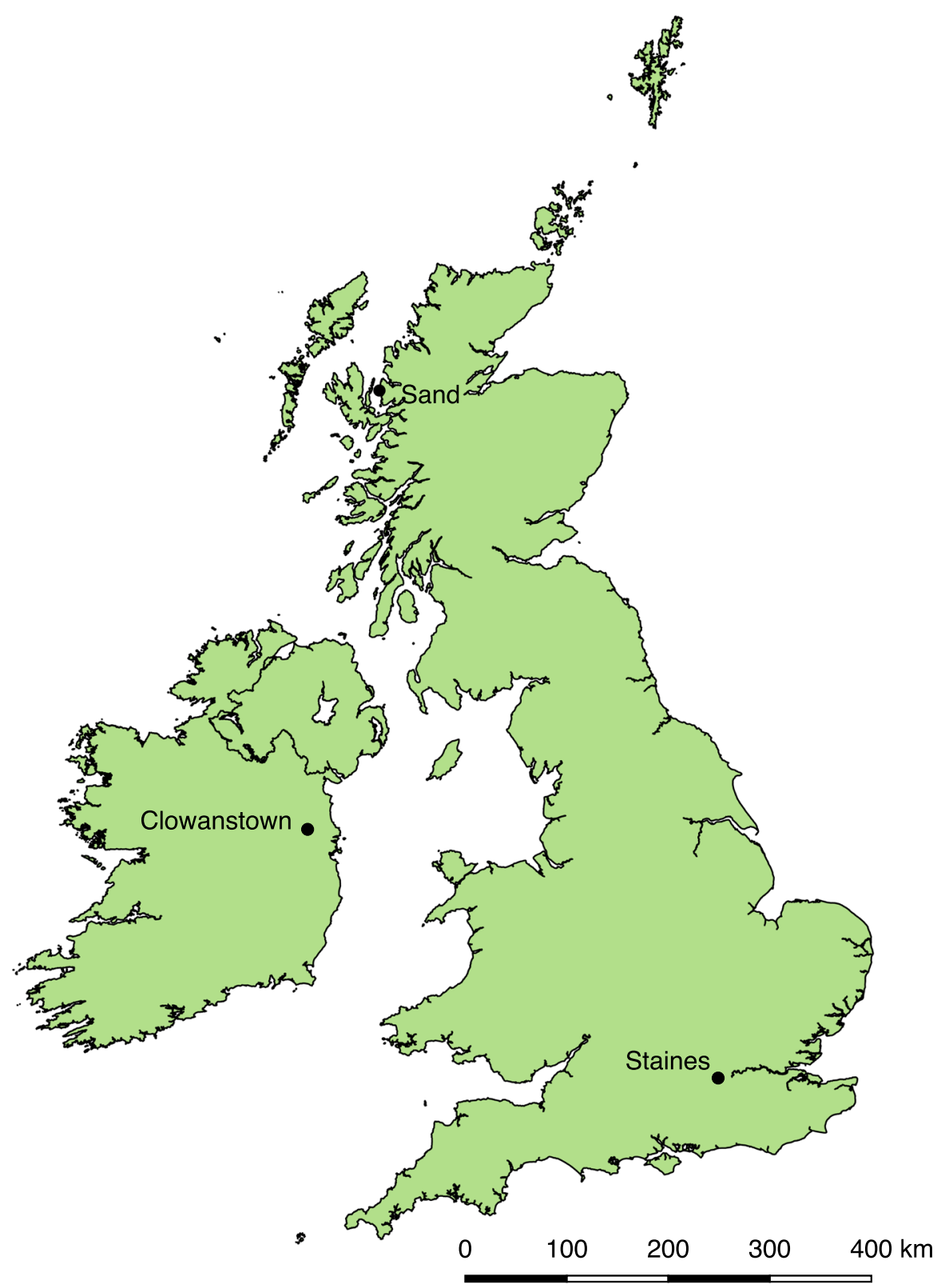

Fig. 2 Location of the three case study sites within Ireland, Scotland and England 
being passed around fixed vertical struts called warps (Fitzgerald 2007). Given the materials used, the weaving of each basket would have had to be executed in a single session of work-which may have lasted several hours depending on the skill of the weaver in question (Bichard 2008). It is worth noting here that these two radiocarbon measurements are not of the same age; there is a statistically significantly difference between them $\left(\mathrm{T}^{\prime}=9.7 ; \mathrm{T}^{\prime} 5 \%=3.8 ; \mathrm{df}=1\right.$; Ward and Wilson 1978). This indicates that occupation at Clowanstown spanned multiple phases of activity and cannot be considered a single 'event'. This is interesting in light of the similarities in technology, as the fish traps appear to have been produced as part of a repeated practice, and to reflect a tradition rather than a single event.

Here we see several different types of temporality at play. The radiocarbon measurements on the fish traps give a date range for when the wood used for them was cut. This narrows our chronological scope for both fish traps from 'Late Mesolithic' to some time in the last three centuries of the sixth millennium or first quarter of the fifth millennium cal BC. Discussions of seasonality offer a different type of resolution, suggesting that these actions were carried out in either autumn or spring. We could (if we wished to) deconstruct the weave of each trap, to establish the precise sequence in which each weft was passed around each warp. It might be tempting to focus on the events of trap construction as the central point on which the 'dating' of the site should focus - the pivotal hours in the narrative of this particular site. From here we could consider the earlier growth and cutting of rose, alder and birch wood. We could think about the construction of the traps, their positioning within the lake (with the assumption that this occurred in spring or autumn) and their subsequent abandonment. We could begin to approach the chronology of this site at a level beyond the events of construction and abandonment. We could also consider the other aspects of the site's archaeology, which might play a key role within the tempo and sequencing of this narrative. At what point was the platform consolidated and utilized? Did the stakes and fish traps form a larger structure, or do they relate to a separate phase of the site's occupation? Where do the sourcing, manufacture and deposition of the flint tools fit in this narrative?

These questions highlight the dangers of prioritizing unusual forms of archaeology within our site narrative. Attempts to capitalize on the rare opportunity to study wooden artefacts in the Irish Mesolithic need to be balanced against the wider understanding of the site and its landscape. The specifics of the fish traps need to be considered not only as moments of manufacture, but in terms of repeated, periodic presence at the site, for humanized, specific reasons, not simply because

Table 2 Radiocarbon measurements on two fish traps from Clownstown, Ireland

\begin{tabular}{lll}
\hline Lab code & Date & $\begin{array}{l}\text { Calibrated BC date range (intercept; } \\
\text { rounded out by 10 years; 95.2\% certainty) }\end{array}$ \\
\hline Beta-231957 & $6190 \pm 50$ & $5320-4990$ \\
Beta-231948 & $5970 \pm 50$ & $5000-4720$ \\
\hline
\end{tabular}


this is what Mesolithic people do, as part of an abstract concept of a 'persistent place'.

\section{Staines, Surrey, England}

A red deer antler beam axe was recovered from the banks of the River Thames at Staines, Surrey, during the nineteenth century (Lawrence 1929). The find had undoubtedly been transported by fluvial action, and there is no immediate contextual data (Elliott 2013). Yet despite these limitations, it is possible to provide some immediate understanding of Mesolithic activity within this region. The axe was made from a left-sided red deer antler, and a prepared break of the middle beam was used to create the angle of the working face. The upper beam and crown were removed by nicking around the circumference of the beam with a flint tool, and then executing a prepared break. The trez-tine was removed. Further modification of the working face involved two phases of scraping-one scraping the working face obliquely and a later phase of longitudinal scraping. A perforation was also created in two phases. A first attempt to drill from the external aspect was quickly abandoned; then a successful perforation was created by drilling through both the external and internal sides of the antler to meet in the centre of the beam. The axe was hafted and used after the perforation was created and the working face finished, before the artefact was deposited in waterlogged sediments within or adjacent to the River Thames. Gnawing marks on the piece suggest that, at some point, it lay exposed at the surface-possibly prior to deposition (Elliott 2013).

The microhistory of this artefact is in contrast with its generic, periodized, broad classification as a 'Mesolithic' find-but it is possible to move between the two. Bonsall and Smith's (1989) dating programme demonstrates that the antler used for this tool was formed in the timespan 4370-3960 cal. BC (OxA-1158; $5350 \pm 100$; $95 \%$ confidence). What both the short-term scale of analysis and the periodized approach fail to identify is that this was in the context of several centuries of rapid and significant change in the nature of material culture and practices across southern England.

Recent Bayesian modelling of rod microlith sites has demonstrated the persistence of these artefacts alongside the use of early agriculture, monuments, pottery, flint mining and the production of polished stone tools in Britain during the forty-first, fortieth and thirty-ninth centuries cal. BC (Griffiths 2014). This example-based on its radiocarbon chronology, and without contextual information- could in fact represent the work of a person engaged in latest hunter-gatherer or earliest farmer lifeways, or indeed some combination of these.

The chronological middle ground is extremely important for our understanding of this item of material culture. The contextual information afforded by radiocarbon chronology - that this thing is potentially situated during a period of dramatic regional change, accompanied by significant new additions to the archaeological record of portable material culture and sites-provides us with important additional understandings which would not be accessible were we only to think of the immediacy of the artefact or its 'Mesolithic-ness'. The wider body of AMS dates from the beam axes in Britain suggest that this artefact is more likely to have been 
made by a person with a fisher-hunter-gatherer lifestyle, with little evidence for the persistence of this particular type of axe into the early Neolithic (Elliott 2015) — but this cannot be confirmed definitively. If we do not explore the potential for noise within datasets we will reproduce our previously held convictions without demur. It is worth saying here that using terms such as Mesolithic, Neolithic, farmer, or hunter-gatherer in relation to people in Britain during the forty-first-thirty-ninth centuries cal BC is now demonstrably problematic and misleading (Griffiths and Gerary 2017).

\section{Sand, Highlands, Scotland}

Our third case study emphasises the importance of moving between the site-specific and the generalised in another way. Excavated as part of the Scotland's First Settlers project (Hardy and Wickham-Jones 2003), the shell midden site at Sand is located within a rock shelter. Test pitting in 1999 established the extent of the midden deposits; this was followed in 2000 by the excavation of c. $16 \%$ of the site, which allowed the stratigraphy of the midden to be ascertained (Hardy 2009). The shell-rich layer was designated 'Context 13' (C13), and overlay an organic-rich, silty deposit, devoid of shells. Evidence of later occupations in a range of prehistoric periods was found in the deposits overlying the Mesolithic midden layers, and the relationship between the deposits implied that the site had been subjected to considerable geological and anthropogenic disturbances over time.

The excavators argue, on the basis of the lack of evidence for vegetation growth within the midden deposits themselves, and the general congruence of the AMS dates from C13 (Table 3), that the Sand shell midden built up quickly and continuously over a relatively short period (Hardy 2009).

When calibrated, the ranges of these dates would suggest that this formation process began (at the very latest) by 6990-6540 cal BC (95\% probability; Start Sand; Fig. 3) and ended by 6600-6470 cal BC (95\% probability; End Sand; Fig. 3). Activity represented by this assemblage of material can be estimated to represent some 130-450 years (DurationSand; 95\% probability; Fig. 4).

The antler from context 13 consists of five tine tips, a large piece of red deer crown and nine fragments of compactor tissue (Fig. 5). The crown demonstrates that the piece was chewed by a large mammal prior to being worked. An AMS sample from this piece produced a date of 6470-6250 cal. BC (95\% confidence; OxA-9280). The Sand assemblage fits into the wider pattern of red deer antler fragmentation seen at Mesolithic shell midden sites across the west coast of Scotland and the Hebrides (Elliott 2013). Red deer antler was processed through the removal of the crown and tines and subsequent longitudinal splitting (via the wedgesplitter technique) to create small fragments of antler suitable for the production of bevel-ended tools. What is notable at Sand is that antler bevel-ended tools themselves are absent from the assemblage. This suggests that the finished products were removed from the site and used elsewhere in the landscape. The small quantities of material present within $\mathrm{C} 13$ may indicate a single working event which occurred at some point within the formation of the deposit. 
Table 3 Radiocarbon measurements from Sand

\begin{tabular}{llll}
\hline Lab code & Material & Date & $\begin{array}{l}\text { Calibrated BC date range (intercept; } \\
\text { rounded out by 10 years; 95.2\% certainty) }\end{array}$ \\
\hline OxA-10384 & Worked bone & $7855 \pm 60$ & $7030-6590$ \\
OxA-10175 & Worked bone & $7825 \pm 55$ & $6820-6520$ \\
OxA-9343 & Birch charcoal & $7765 \pm 50$ & $6690-6470$ \\
OxA-9281 & Worked bone & $7715 \pm 55$ & $6650-6450$ \\
OxA-9282 & Worked bone & $7545 \pm 50$ & $6470-6260$ \\
OxA-9280 & Worked antler & $7520 \pm 50$ & $6470-6250$ \\
\hline
\end{tabular}

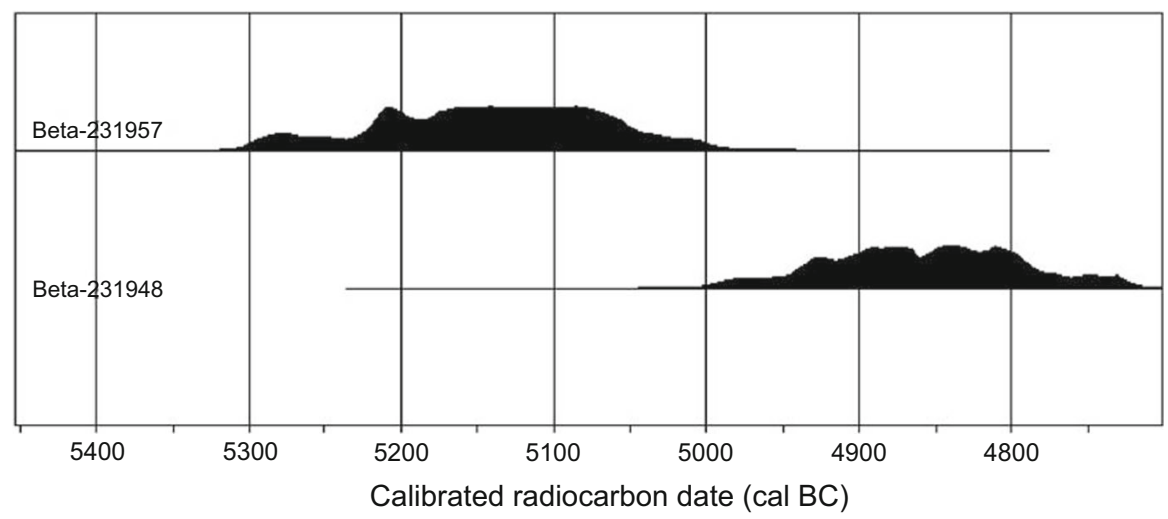

Fig. 3 The calibrated radiocarbon dates from fish traps from Clowanstown, Meath

The temporality of antler-working at Sand has a number of important features. Based on the radiocarbon chronology presented here, the assemblage formed over a period of 130-450 years (95\% probability; DurationSand; Fig. 4). This is more than the lifespan of several individuals. We are left with a number of options, either residual materials - some of them quite old - are used as part of a short-lived occupation at the site, or occupation at the site actually occurred over a period of time which is chronologically significant in terms of human lifespans and associated social choices (Fig. 6).

There is a tension between the interpretation from the site that the shell midden built up quickly and continuously over a relatively short period of time (Hardy 2009) and the radiocarbon chronological data. This is interesting in terms of deposit formation processes, and fundamentally, in terms of the nature of occupation of the site, the traditions and the human lifeways associated with Mesolithic occupation. Antler was apparently gathered from the environment (rather than being taken directly from an animal carcass in butchery) and brought to Sand specifically for working. The products of this working were then carried elsewhere for use-linking other, as yet undiscovered, sites within the landscape to this particular narrative after the event of production. The presumed use and final deposition of these 


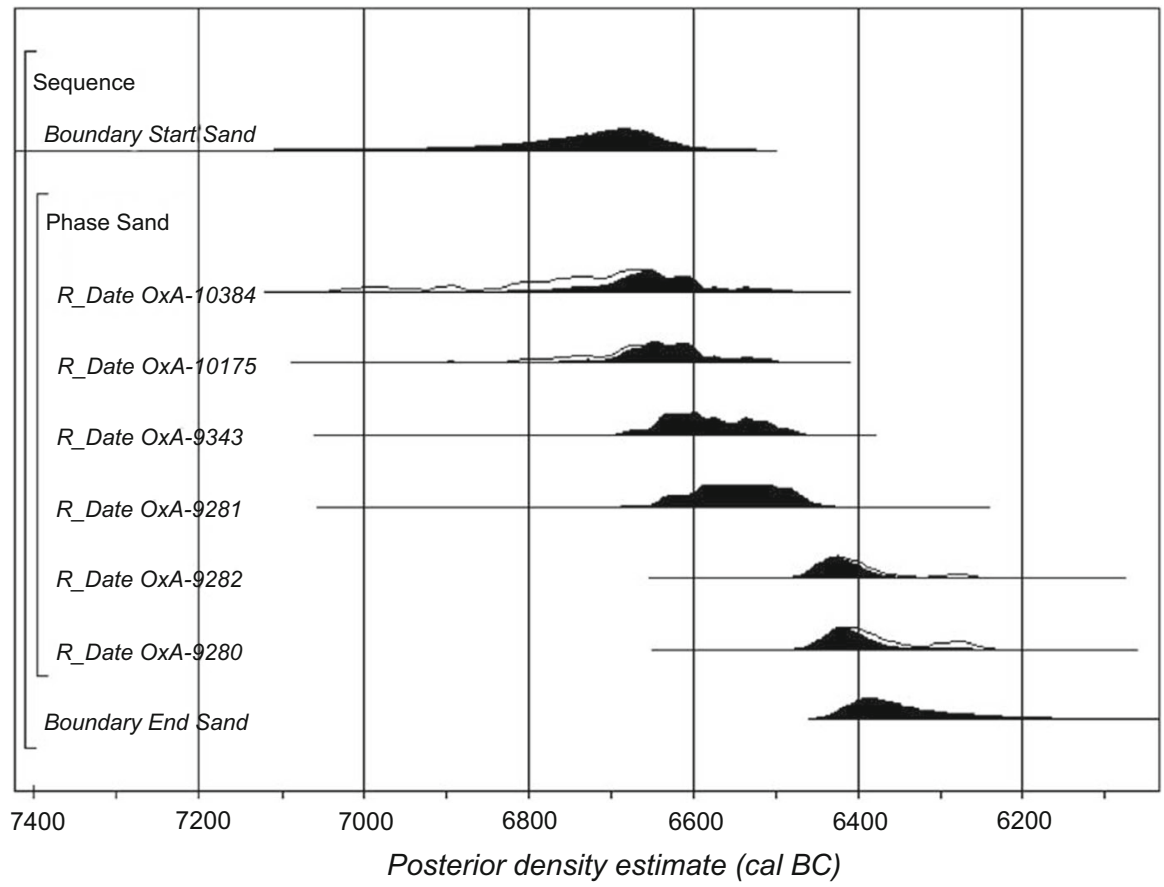

Fig. 4 A Bayesian statistical model of the radiocarbon dates from Context 13, Sand, estimating the start and end of activity associated with the context

\section{Context 13}
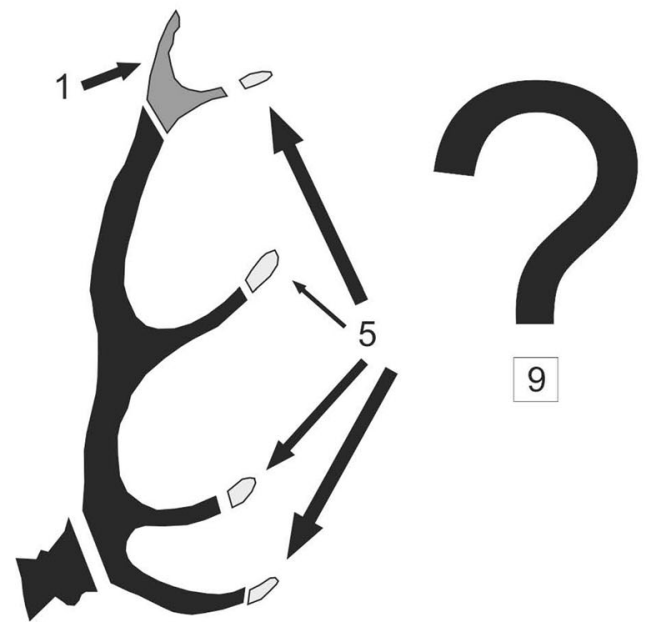

\begin{tabular}{|l|l|}
\hline Element & Quantity \\
\hline Crown & 1 \\
\hline Tine tip & 5 \\
\hline Unknown & 9 \\
\hline
\end{tabular}

Fig. 5 Fragmentation of red deer antler from Sand Context 13 


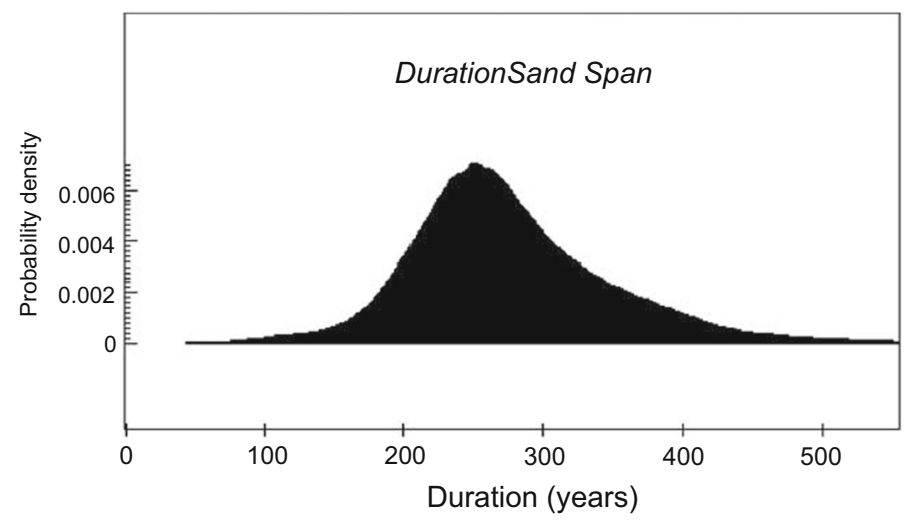

Fig. 6 An estimate for the duration of activity represented by the radiocarbon dates from Context 13, Sand, and calculated as in the Phase shown in the model in Fig. 3

artefacts reflects the later chapters of this chaîne opératoire. Antlerworking is a small part of the 'event' of the formation of Context 13, which in turn forms part of a longer narrative extending beyond the site in both time and space.

The tension-between the exploded spatial location of the site and contexts of the materials, the duration and temporality of occupation, and the formation of the context which is explored archaeologically-is of fundamental interest to our understandings of the nature of social practice and human choices at this site. Neither the short-term approaches to the archaeological deposits with the context inferred as an event, nor the abstracted nature of the chronology of 'Mesolithic' antler-working techniques would help us unpick this narrative tension.

\section{Conclusions}

Since the start of Mesolithic enquiries, the variability of the archaeological record has been noted; we argue that while the nature of Mesolithic material is specific, the issue of moving from the specific evidence of individual sites or artefacts to wider narratives is shared by other archaeological periods. While in Mesolithic studies the gaps in our evidence are notable, it is not this but rather our approaches to this evidence that have the greatest potential to limit our interpretations. When our spatial and temporal datasets are limited, the challenges involved in moving beyond a series of generalizations based on highly specific examples are all the greater.

The case studies above demonstrate the range of scales which our current methods of analysis offer us in the study of material culture. Different forms of analysis provide different types of insights into material conditions in the past, which we as archaeologists use to form our own narratives and understandings. Yet these different narrative forms are seldom, if ever, readily compatible. By illustrating some of the unique ways in which Mesolithic chronological concerns are related to our narratives we hope to show the variety of different challenges and opportunities in the pursuit of Mesolithic lives. We feel that the key to achieving 
this is to continue to critically consider the relationships which form between the different types of knowledge.

Throughout this paper, we have shown that, despite differing histories of research in Mesolithic studies in Ireland and Britain, the challenges are strikingly similar in both contexts. The impact of AMS dating, Bayesian modelling of chronological data, and chaîne opératoire approaches in material culture, has led to shared concerns in relation to the study of organic material culture, including a growing emphasis on the micro-scale and intimate in Mesolithic narratives.

When dealing with archaeological datasets as varied as those of the Irish and British Mesolithic, we must be especially conscious that how we conduct our research has implications for how we write our narratives. This applies directly to the use of the name 'Mesolithic', as it does to the basic disciplinary axioms of time and space. We need to be more explicit about the structuring role that the precision of our chronological and spatial resolution affords us; this applies as much to how we write about the period as to the precision available to us. Data do not speak for themselves. More data will not necessarily resolve our ability to produce the 'correct' reconstructions of Mesolithic lives. Even working in uniquely wellpreserved sites does not exempt us from the need to problematize these aspects of our discipline; in terms of appreciating the nuance and variation of the past, 'dating the Mesolithic' is as redundant an exercise as giving school children king lists to learn by rote. 'The Mesolithic' is entirely a contemporary heuristic construct. The trick will be to move between the scales of evidence, from the atypical and exceptional sites through to the individual evidence from events, by way of a chronologically and narratively broader approach. We suggest that an explicit recognition of the various ways chronology structures our narratives, combined with the use of heuristic devices that force us to move between analytical scales, is a good place to start.

Open Access This article is distributed under the terms of the Creative Commons Attribution 4.0 International License (http://creativecommons.org/licenses/by/4.0/), which permits unrestricted use, distribution, and reproduction in any medium, provided you give appropriate credit to the original author(s) and the source, provide a link to the Creative Commons license, and indicate if changes were made.

\section{References}

Bailey, G. (2007). Time perspectives, palimpsests and the archaeology of time. Journal of Anthropological Archaeology, 26, 198-223.

Barton, N., \& Roberts, A. (2004). The Mesolithic period in England: Current perspectives and new research. In A. Saville (Ed.), Mesolitihc Scotland and its neighbours: The early holocene prehistory of Scotland, its British and Irish context, and some northern European perspectives (pp. 339-358). Edinburgh: Society of Antiquaries of Scotland.

Barton, R., Berridge, P., Walker, M., \& Bevins, R. (1995). Persistent places in the Mesolithic landscape: An example from the Black Mountain uplands of South Wales. Proceedings of the Prehistoric Society, 61, 81-116.

Bayliss, A., \& Woodman, P. (2009). A new Bayesian chronology for Mesolithic occupation at Mount Sandel, Northern Ireland. Proceedings of the Prehistoric Society, 75, 101-123.

Bichard, M. (2008). Baskets in Europe. Fyfield Wick: Oxon. 
Bishop, A. (1914). An Oransay shell-mound: A Scottish pre-Neolithic site. Proceedings of the Society of Antiquaries of Scotland, 48, 52-108.

Bonsall, C., \& Smith, C. (1989). Late Palaeolithic and Mesolithic bone and antler artifacts from Britain: First reactions to accelerator dates. Mesolithic Miscellany, 10, 33-38.

Bonsall, C., \& Smith, C. (1992). New AMS C14 dates for antler and bone artifacts from Great Britain. Mesolithic Miscellany, 13, 28-34.

Bonsall, C., Smith, C., \& Saville, A. (1995). Direct dating of Mesolithic antler and bone artifacts from Great Britain: New results for bevelled tools and red deer antler mattocks. Mesolithic Miscellany, 16, 2-10.

Burkitt, M. (1926). Our early ancestors: An introductory story of Mesolithic, Neolithic and Copper Age cultures in Europe and adjacent regions. Cambridge: Cambridge University Press.

Clark, G. (1932). The Mesolithic Age in Britain. London: Cambridge University Press.

Clark, G. (1954). Excavations at Star Carr: An early Mesolithic site at Seamer near Scarborough, Yorkshire. Cambridge: Cambridge University Press.

Clark, G. (1966). The invasion hypothesis in British archaeology. Antiquity, 40, 172-189.

Clarke, D. (1973). Archaeology: The loss of innocence. Antiquity, 47, 6-18.

Conneller, C. (2005). Moving beyond sites: Mesolithic technology in the landscape. In N. Milner \& P. Woodman (Eds.), Mesolithic studies at the beginning of the 21st century (pp. 42-55). Oxford: Oxbow Books.

Conneller, C. (2006). The space and time of the châine opératoire: Technological approaches to past landscapes. Archaeological Review from Cambridge, 21(1), 38-44.

Conneller, C., Bayliss, A., Milner, N., \& Taylor, B. (2016). The resettlement of the British landscape: Towards a chronology of Early Mesolithic lithic assemblage types. Internet Archaeology. https:// doi.org/10.11141/ia.42.12.

Conneller, C., Milner, N., Taylor, B., \& Taylor, M. (2012). Substantial settlement in the European Early Mesolithic: New research at Star Carr. Antiquity, 86(334), 1004-1020.

Costa, L., Sternke, F., \& Woodman, P. (2005). Microlith to macrolith: The reasons behind the transformation of production in the Irish Mesolithic. Antiquity, 79(303), 19-33.

Daniel, G. (1967). The origins and growth of archaeology. Harmondsworth: Penguin Books.

David, E. (1999). L'industrie en matières dures animales du Mésolithique ancien et moyen en Europe du Nord. Contribution de l'analyse technologique à la définition du Maglemosien. PhD thesis, Université Nanterre-Paris X, Paris.

David, E., McCartan, S., Molin, F., \& Woodman, P. (2015). 'Fishing' Mesolithic settlement-subsistence systems using notions of economy of debitage and raw material towards production of bone points. In N. Bicho, C. Dietry, T. D. Price, \& E. Cunha (Eds.), MUGE 150th: The 150th Anniversary of the discovery of the shell middens (pp. 173-188). Newcastle: Cambridge Scholars Publishing.

Dumont, J. (1988). A microwear analysis of selected artefact types from the Mesolithic sites of Star Carr and Mount Sandel. Oxford: British Archaeological Reports.

Elliott, B. (2013). Antlerworking practices in Mesolithic Britain. PhD thesis, University of York.

Elliott, B. (2015). Facing the chop: Redefining British antler mattocks to consider larger-scale maritime networks in the early fifth millennium cal BC. European Journal of Archaeology, 18(2), 222-244.

Finlay, N. (2006). Gender and personhood. In C. Conneller \& G. Warren (Eds.), Mesolithic Britain and Ireland: New approaches (pp. 35-60). Stroud: Tempus.

FitzGerald, M. (2007). Catch of the day at Clowanstown, Co., Meath. Archaeology Ireland, 21(4), 12-15.

Fredengren, C. (2009) Lake Platforms at Lough Kinale: Memory, reach and place. A Discovery Programme project in the Irish Midlands. In S. McCartan, R. Schulting, G. Warren, \& P. Woodman (Eds.), Mesolithic horizons: Papers presented at the Seventh International Conference on the Mesolithic in Europe, Belfast (pp. 882-887). Oxford: Oxbow.

Gräslund, B. (1987). The birth of prehistoric chronology: Dating methods and dating systems in nineteenth-century Scandinavian archaeology. Cambridge: Cambridge University Press.

Griffiths, S. (2014). Points in time: The Mesolithic-Neolithic transition and the chronology of late rod microliths in Britain. Oxford Journal of Archaeology, 33(3), 221-243.

Griffiths, S., \& Gerary, B. (2017). The Mesolithic-Neolithic transition and the chronology of the "elm decline': A case study from Yorkshire and Humberside, United Kingdom. Radiocarbon, 59(5), 1321-1345.

Griffiths, S., \& Robinson, E. (2018). The 8.2 ka BP Holocene climate change event and human population resilience in northwest Atlantic Europe. Quaternary International, 465(B), 251-257. 
Hardy, K. (2009). Excavation at Sand, rockshelter. In K. Hardy \& C. Wickham-Jones (Eds.), Mesolithic and later sites around the Inner Sound, Scotland: The work of the Scotland's First Settlers project 1998-2004. Scottish Archaeological Internet Reports 31. York: Society of Antiquaries of Scotland.

Hardy, K., \& Wickham-Jones, C. (2003). Scotland's first settlers: An investigation into settlement, territoriality and mobility during the Mesolithic in the Inner Sound, Scotland. In L. Larsson, H. Kindgern, K. Knuttson, D. Loeffler, \& A. Akerlund (Eds.), Mesolithic on the move: Papers presented at the Sixth International Conference on the Mesolithic in Europe, Stockholm 2000 (pp. 369-384). Oxford: Oxbow.

Jacobi, R. (1978). Northern England in the eighth millennium BC: An essay. In P. Mellars (Ed.), The early post-glacial settlement of northern Europe (pp. 295-332). London: Duckworth.

Lacaille, A. (1966). Mesolithic facies in the transpontine fringes. Surrey Archaeological Collection, 66, $1-43$.

Lane, P., \& Schadla-Hall, R. (2004). The many ages of Star Carr: Do 'cites' make 'sites'? In A. Barnard (Ed.), Hunter-gatherers in history, archaeology and anthropology (pp. 145-162). Oxford: Berg Publishers.

Lawrence, G. (1929). Antiquities from the middle Thames. Archaeological Journal, 86, 69-98.

Legge, A., \& Rowley-Conwy, P. (1988). Star Carr revisited: A re-analysis of the large mammals. London: University of London.

Little, A. (2014). Clonava island revisited: A story of cooking, plants and re-occupation during the Irish Late Mesolithic. In Proceedings of the Royal Irish Academy. Section C. Archaeology, Celtic studies, history, linguistics and literature (Vol. 114(C), pp. 35-55).

May, A. (1939). Some pointed bones, flints, and stone discs from the lower River Bann. Journal of the Royal Society of Antiquaries of Ireland, 9(3), 152-161.

McQuade, M., \& O’Donnell, L. (2007). Late Mesolithic fish traps from the Liffey estuary, Dublin, Ireland. Antiquity, 81(313), 569-584.

Mellars, P. (1976). Settlement patterns and industrial variability in the British Mesolithic. In G. Sieveking, I. Longworth, \& K. Wilson (Eds.), Problems in economic and social archaeology (pp. 375-400). London: Duckworth.

Mellars, P., \& Dark, P. (1998). Star Carr in context: New archaeological and palaeoecological investigations at the Early Mesolithic site of Star Carr, North Yorkshire. Cambridge: McDonald.

Milner, N. (1999). Pitfalls and problems in analysing and interpreting the seasonality of faunal remains. Archaeological Review from Cambridge, 16(1), 51-67.

Milner, N., Craig, O., Bailey, G., \& Andersen, H. (2006). A response to Richards and Schulting. Antiquity, 308, 456-458.

Mitchell, G. (1955). The Mesolithic site at Toome Bay, Co., Londonderry. Studies in Irish Quaternary deposits No. 10. Ulster Journal of Archaeology, 18, 1-16.

Mitchell, G. (1970). Some chronological implications of the Irish Mesolithic. Ulster Journal of Archaeology, 33, 3-14.

Mossop, M. (2009). Lakeside developments in County Meath, Ireland: A Late Mesolithic fishing platform and possible mooring at Clowanstown 1. In S. McCartan, R. Schulting, G. Warren, \& P. Woodman (Eds.), Mesolithic horizons: Papers presented at the Seventh International Conference on the Mesolithic in Europe, Belfast (pp. 895-899). Oxford: Oxbow.

Myers, A. (1987). All shot to pieces? Inter-assemblage variability, lithic analysis and Mesolithic assemblage 'types': Some preliminary observations. In A. Brown \& M. Edmonds (Eds.), Lithic analysis and later British Prehistory: Some problems and approaches (pp. 137-153). Oxford: British Archaeological Reports.

Pluciennik, M. (2002). The invention of hunter-gatherers in seventeenth-century Europe. Archaeological Dialogues, 9, 98-150.

Reynier, M. (2005). Early Mesolithic Britain: Origins, development and directions. Oxford: British Archaeological Reports.

Richards, M., Schulting, R., \& Hedges, R. (2003). Sharp shift in diet at onset of Neolithic. Nature, 425, 366.

Rowley-Conwy, P. (1996). Why didn't Westropp's Three Age System catch on? Antiquity, 70(270), 940-944.

Smith, C. (1989). British Antler mattocks. In C. Bonsall (Ed.), The Mesolithic in Europe: Papers presented at the third international symposium, Edinburgh 1985 (pp. 272-283). Edinburgh: J. Donald. 
Smith, C., \& Bonsall, C. (1999). Stone Age studies in the British Isles: The impact of accelerator dating. Mémoires de la Société Préhistorique Française, 26, 249-257.

Spikins, P. (2002). Prehistoric people of the Pennines: Reconstructing the lifestyles of Mesolithic huntergatherers on Marsden Moor. Leeds: West Yorkshire Archaeology Service on behalf of West Yorkshire Joint Services.

Switsur, V., \& Jacobi, M. (1979). A radiocarbon chronology for the early postglacial stone industries of England and Wales. In R. Berger \& H. Suess (Eds.), Radiocarbon dating: Proceedings of the ninth international conference, Los Angeles and La Jolla, 1976 (pp. 41-68). Berkley: University of California Press.

Waddington, C. (2007). Mesolithic settlement in the North Sea Basin: A case study from Howick. Oxford: Oxbow.

Ward, G., \& Wilson, S. (1978). Procedures for comparing and combining radiocarbon age determinations: A critique. Archaeometry, 20, 19-31.

Warren, G., Davis, S., McClatchie, M., \& Sands, R. (2013). The potential role of humans in structuring the wooded landscapes of Mesolithic Ireland: A review of data and discussion of approaches. Vegetation History and Archaeobotany, 23(5), 629-646.

Westropp, H. (1866). Analogous forms of implements among early and primitive races. Memoirs of the Anthropological Society, 2, 288-293.

Westropp, H. (1872). Prehistoric phases. London: Bell \& Daldy.

Whelan, B. (1951). A bone industry from the Lower Bann. Belfast: Archaeological Research Publications (Northern Ireland).

Whittle, A., Healy, F., \& Bayliss, A. (2011). Gathering time: Dating the Early Neolithic enclosures of southern Britain and Ireland. Oxford: Oxbow.

Woodman, P. (1977). Recent excavations at Newferry, Co. Antrim. Proceedings of the Prehistoric Society, 43, 155-199.

Woodman, P. (1978). The Mesolithic in Ireland: Hunter-gatherers in an insular environment. BAR British Series, 58. Oxford: British Archaeological Reports.

Woodman, P. (1981). The postglacial colonization of Ireland: The human factors. In D. O'Corráin (Ed.), Irish Antiquity: Essays and studies presented to Professor M. J. O'Kelly (pp. 93-110). Cork: Tower Books.

Woodman, P. (2015). Ireland's first settlers: Time and the Mesolithic. Oxford: Oxbow.

Woodman, P., McCarthy, M., \& Monaghan, N. (1997). The Irish Quaternary fauna project. Quaternary Science Reviews, 16, 129-159.

Worsaae, J. J. A. (1861). Om Tvedelingen af Stenalderen. Oversigt over det Kongelige Danske videnskabernes selskabs forhandlinger og dets medlemmers Arbeider i året, 1861(10), 233-294.

Zvelebil, M. (1998). What's in a name: The Mesolithic, the Neolithic, and social change at the Mesolithic-Neolithic transition. In M. Edmonds \& C. Richards (Eds.), Understanding the Neolithic of northwestern Europe (pp. 1-36). Glasgow: Cruithne Press.

Zvelebil, M. (2002). The invention of hunter-gatherers in seventeenth century Europe? A comment on Mark Pluciennik, Archaeological Dialogues, 9(2), 123-129. 